\title{
Publisher Correction: Identification of plasma modes in Galactic turbulence with synchrotron polarization
}

Heshou Zhang (D), Alexey Chepurnov, Huirong Yan (D), Kirit Makwana, Reinaldo Santos-Lima and Sarah Appleby

Correction to: Nature Astronomy https://doi.org/10.1038/s41550-020-1093-4, published online 25 May 2020.

In the version of this Article originally published, the angles $\varphi$ and $\varphi_{\mathrm{s}}$ were incorrectly labelled in Fig. 1a. This has now been corrected. The original and corrected versions of the panel are shown below.

Original

a

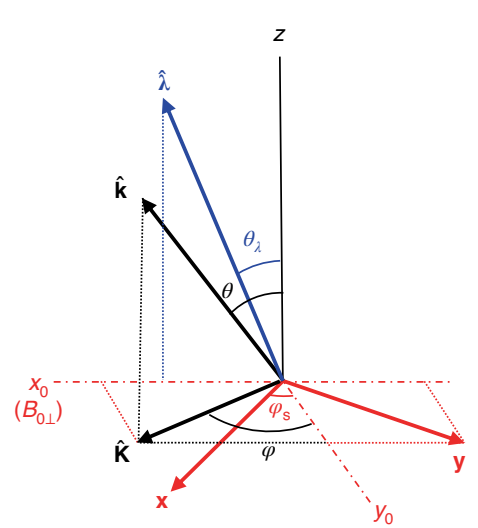

Corrected

a

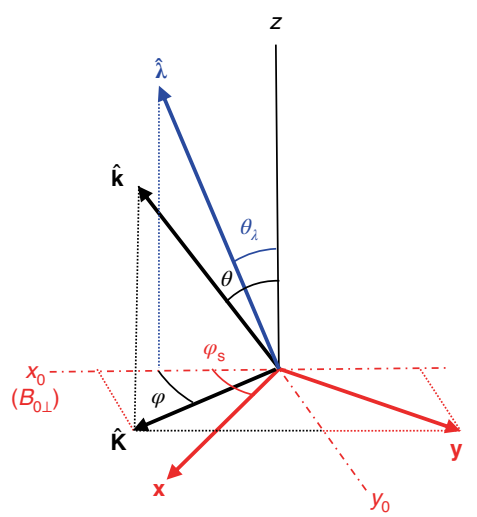

Fig. 1 | Original and Corrected.

Published online: 18 June 2020

https://doi.org/10.1038/s41550-020-1152-x

( $)$ The Author(s), under exclusive licence to Springer Nature Limited 2020 